\title{
Residents talking to Ontario over new entry program
}

$\mathrm{M}$ ore than three months after the Ontario government imposed conditions on how new family medicine graduates can practise in the province, details remain elusive - a situation the Professional Association of Residents of Ontario (PARO) hopes to clarify at a January meeting with the Ministry of Health and Long-Term Care.

On Oct. 1, during the province's second round of unilateral cuts to physician fees and in the continued absence of a new Physician Services Agreement, the ministry announced its New Graduate Entry Program (NGEP). The NGEP imposes conditions on how family physicians practise in their first three years. In particular, it is aimed at new doctors who want to join a Family Health Network (FHN) or Family Health Organization (FHO) that is not located in a ministryidentified "high physician needs area."

The NGEP places an upper limit on physician salaries during each of the three years, starting at $\$ 162000$ with annual increases, reaching $\$ 207000$ by the third year. Physicians will also be subject to a cap on fee-for-service claims for services performed outside the FHN/FHO (no compensation the first year and a maximum of \$28 000 for each of the second and third years).

In addition, physicians will be required to meet monthly patient enrolment targets and commit to enrolling new patients who have not been taken on by another physician in the FHN/FHO group or the group itself. The monthly enrollment target ranges from 14 to 75 patients per month (depending on the given month and year), with a combined cumulative enrollment target of 1200 patients by the end of the program.

Physicians joining the NGEP commit to a minimum of three years of service and can transition to regular compensation under the FHN/FHO

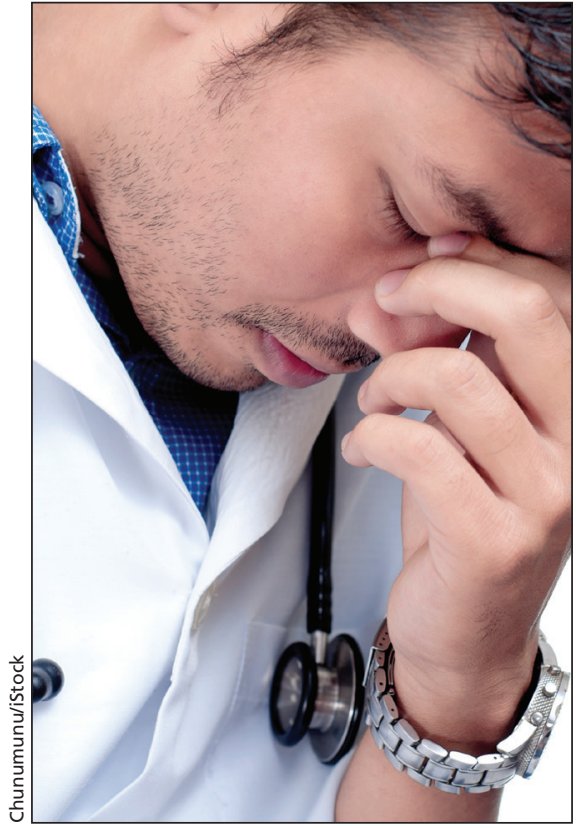

Ontario's New Graduate Entry Program imposes conditions on how family physicians practise in their first three years, but details remain elusive.

agreement only if they have met or exceeded ministry-prescribed targets around "access," "preventive care" and "patient experience."

Many specifics about the program, such as the minimum requirements for the prescribed service targets, are still unknown. The ministry is imposing these restrictions on practice even though an estimated 800000 Ontarians are without a family doctor.

In justification of the NGEP, the ministry noted in an email that it "creates one more option for physicians interested in establishing their practice in Ontario" and "is only one of many practice options [available to new graduate family physicians]."

However, Dr. Natasha Snelgrove, president of PARO, says they are approaching the proposed program with "cautious concern." She says she wor- ries that the NGEP may limit new graduates' in "practising to the full scope of their abilities." "The proposed cap on outside billings ... means new grads may not be able to practise in emergency care, nursing home care or other aspects of family practice."

The NGEP is an untested model. The ministry says that the "program is designed to respond to a unique situation related to implementation of the ministry's Managed Entry policy," so they were unable to look elsewhere for direction when crafting the program. However, in its email response, the Ministry says it tried "repeatedly to engage the Ontario Medical Association (OMA) in discussions/negotiations with respect to the [NGEP], but the OMA refused to participate in any discussions outside of a broader Physician Services Agreement negotiation."

As far as PARO is aware, none of the residents that it represents were consulted prior to implementation of the program. However, the ministry notes that it has "heard concerns about certain components of the [NGEP] and are currently reviewing it."

Meanwhile, PARO has established a team to review the details of the program so it can provide the ministry with specific questions and concerns at the January meeting. PARO's bid for a meeting with the Minister of Health and Long-term Care was unsuccessful; instead, representatives will meet with the Health Human Resources Division. Snelgrove says that, following the meeting, "[PARO's] planning to continue to advocate that new grads have equitable access to practice opportunities ... once we see how that meeting goes, then we'll know which direction we'll need to take things." - Marc Napoleone, Ottawa, Ont.

CMAJ 2016. DOI:10.1503/cmaj.109-5216 